\title{
Redesigning the Student Learning Approach through Personality Types and Pedagogies, A Case Study in an Undergraduate Engineering Course
}

\author{
Corinna Fleischmann ${ }^{1}$, Elizabeth Nakagawa ${ }^{1}$, Tyler Kelley ${ }^{2, *}$ \\ ${ }^{1}$ Civil Engineering Section, United States Coast Guard Academy, USA \\ ${ }^{2}$ Department of Management, United States Coast Guard Academy, USA
}

Copyright $(\mathcal{C} 2016$ by authors, all rights reserved. Authors agree that this article remains permanently open access under the terms of the Creative Commons Attribution License 4.0 International License

\begin{abstract}
As the National Science Foundation and engineers throughout the world seek to strengthen the future of the engineering profession, the Civil Engineering (CE) program at the United States Coast Guard Academy embodies this initiative with a student focused approach. One course in particular, Materials for Civil and Construction Engineers (CE Materials), was restructured focusing on multiple pedagogies (e.g. traditional chalkboard writing, presentations, field trips, labs, etc.) to appeal to different student learning preferences and create a more inclusive learning environment. Utilizing the Myers-Briggs Type Indicator, instructors focused on the first two dichotomies, Extroversion vs. Introversion and Sensing vs. Intuition. With an innovative approach towards CE Materials, the goal of stimulating independent thinkers and assisting students with the retention of core course material is being achieved across a range of student learning preferences. By teaching the course in a way that encompasses all learning preferences, a greater breadth of students can succeed in and enjoy a civil engineering curriculum.
\end{abstract}

Keywords Pedagogy, Learning Types, Civil Engineering, Undergraduate

\section{Introduction}

Typical civil engineering courses rely heavily on quantifiable material, design work and calculation. As a result, the classic engineering curriculum generally attracts students who prefer numbers and a reference based learning style. Therefore, when a course varies from this style and relies more heavily on memorization than the use of a calculator, the typical engineering student is less stimulated by the material and perceives the course as "soft". At the United States Coast Guard Academy (USCGA), Materials for Civil and Construction Engineers (CE Materials) - a required course in the $\mathrm{CE}$ curriculum - is one such course. CE Materials introduces students to the construction subfield and is essential to student understanding of materials utilized in the CE profession. Over the course of the semester, students are familiarized with civil engineering construction materials such as aggregates, concrete, asphalt concrete, steel, wood, and geosynthetic materials. CE Materials has some design work and calculations typical of an engineering course but relies heavily on memorization of basic material properties. Due to the lack of" hard engineering" (i.e. calculations and lengthy designs), CE Materials is not viewed as a "typical" CE undergraduate engineering course and has historically been viewed by students as "weak" and "boring." These perceptions have become a source of innovation within the program as faculty seek new and exciting methods to teach and inspire CE students in all required courses.

\section{USCGA Civil Engineering Program}

As the nation's smallest service academy, the USCGA's student body, of approximately 1000 cadets, is tasked with the dual mission of earning a Bachelor's of Science Degree and training service ready Ensigns to commission in the United States Coast Guard. Due to this two-pronged mission, cadets in the Civil Engineering program face challenging time constraints as they are required to complete an Accreditation Board for Engineering and Technology (ABET) accredited CE curriculum in addition to military requirements. The demanding schedule results in just one free elective over the four year course of study. Graduates of the USCGA CE program have the opportunity to pursue a variety of career paths within the U.S. Coast Guard (engineering and non-engineering), therefore the $\mathrm{CE}$ program educational objectives (PEOs) are purposely broad and aim to meet the needs of the U.S. Coast Guard in and out of the field of Civil Engineering. The CE PEOs are to 
produce graduates who':

1) Are prepared for professional practice in engineering positions as U.S. Coast Guard Junior Officers

2) Are prepared for a variety of U.S. Coast Guard career paths, based on their abilities to apply fundamental engineering principles in dynamic technological environments.

3) Have the ability and desire to continue to grow intellectually and professionally.

4) Are prepared to provide appropriate civil engineering expertise to the U.S. Coast Guard.

As the primary accession point for Civil Engineers into the U.S. Coast Guard, the quality and quantity of USCGA CE graduates directly affects the Civil Engineering community within the U.S. Coast Guard. The ability of our graduates to attain professional licensure as well as professional practice in alternate Coast Guard career paths is of the utmost importance.

\section{Materials for Civil and Construction Engineers}

The Materials for Civil and Construction Engineers (CE Materials) is a 4 credit course offered at USCGA and a requirement for students obtaining a Civil Engineering Degree. As an introductory course to the construction subfield, CE Materials teaches students to identify and analyze relevant civil engineering materials as well as construction equipment and techniques. The emphasis of the course is placed on understanding the engineering properties of these materials, selection of materials and practical construction methods and performance. There is a design component to the course which includes the designing and testing both a Portland cement concrete (PCC) mix and hot mixed asphalt (HMA) concrete. While there are some design elements of the course, the focus of the course is on student obtainment of a broad spectrum of material knowledge relying more heavily on memorization skills than design calculations. Upon course completion, students should have a basic understanding of the material and engineering properties associated with civil engineering materials and should be able to articulate how these properties affect selection in construction and in service performance.

\section{MBTI Methodology}

The goal of redesigning CE Materials was to stimulate independent thinkers and assist students with the retention of core course material across a range of student learning preferences by designing new and innovative lesson plans. These lesson plans aim at presenting the material in a way that all learning types are reached so that overall a greater breadth of students will succeed. In order to determine the best methods to accomplish this objective, the Myers-Briggs Type Indicator (MBTI) was first utilized. "The essence of the
MBTI theory is that much seemingly random variation in behavior is actually quite orderly and consistent, being due to basic differences in the way an individual prefers to use their perception and judgment." ${ }^{2}$ By identifying the orderly and consistent behaviors and categorizing those behaviors based on Carl Jung's study on extroversion and introversion, it was further expanded upon and "subdivided into eights types by identifying two pairs of opposite mental functions: two opposite perceiving functions and two opposite judging functions." ${ }^{2}$ Isabel Myers and Katherine Briggs then interpreted Jung's theory in the MBTI personal type inventory, which is widely used today to give individuals a better understanding of their personality preferences and how they impact their interactions with others. Framing the course based on this theory gave the best opportunity to achieve the end goal of being able to excite and reach the entire audience across individual learning preferences.

Employing MBTI as a learning model, instructors focused specifically on the first two dichotomies, Extroversion vs. Introversion (E-I), and Sensing vs. Intuition (S-N). First, the E-I dichotomy focuses on where people direct and get their energy from. More specifically students who have a preference towards $\mathrm{E}$ get and focus their energy on the outside world, while students who have a preference towards I focus their energy on the inside world ${ }^{2}$. Determining how and where students get their energy from is integral to the first aspect of the goal - exciting students on the subject. Secondly, the S-N dichotomy focuses on how people perceive or take in information. Understanding how students take in the information is essential towards achieving the second aspect of the goal - reaching the entire audience. More specifically students with a preference towards S like information that is to the point and matter of fact, while students with a preference towards $\mathrm{N}$ like information that is focused on the bigger picture. $^{2}$

\section{Current CE Materials Course Assessment}

To redesign the course, the baseline curriculum was dissected and lesson delivery methods were categorized based on tacit (experiential) or explicit (articulated) knowledge. Once all the activities were defined, an evaluation of the current course schedule revealed that 23 out of the 29 classroom instruction, not including laboratory, were primarily delivered by the instructor and focused on explicit knowledge (Table 1). This analysis indicated an absence of tacit knowledge in the course, indicating a potential area for improvement. Five years ago, when one faculty member retired, the course underwent its first iteration of change. Prior to this change, tacit instruction existed solely during the designated laboratory periods. In 2010, limited tacit instruction was introduced into the classroom portion of the course with success. With minimal changes implemented in course since 2010, the first step in this current assessment was to link the existing classroom 
delivery methods to the explicit or tacit dichotomies (Table 1) thereby identifying potential areas for improvement.

Table 1. Course Evaluation Matrix

\begin{tabular}{|c|c|c|}
\hline Classroom Activities & Delivery Method & Dichotomies Link \\
\hline \multicolumn{3}{|c|}{ Previous Course } \\
\hline Exams & Explicit & $\mathrm{I}, \mathrm{S} / \mathrm{N}$ \\
\hline $\begin{array}{c}\text { Fill in the blank } \\
\text { outline }\end{array}$ & Explicit & $\mathrm{I}, \mathrm{S} / \mathrm{N}$ \\
\hline $\begin{array}{l}\text { Homework - short } \\
\text { answer }\end{array}$ & Explicit & $\mathrm{I}, \mathrm{S}$ \\
\hline $\begin{array}{c}\text { In class } \\
\text { demonstrations } \\
\text { (physical) }\end{array}$ & Tacit & $\mathrm{E}, \mathrm{S} / \mathrm{N}$ \\
\hline Laboratory & Tacit & E,S \\
\hline Laboratory Reports & Explicit & $\mathrm{I}, \mathrm{S}$ \\
\hline Videos & Explicit & $\mathrm{I}, \mathrm{S} / \mathrm{N}$ \\
\hline $\begin{array}{l}\text { Writing lesson on the } \\
\text { board }\end{array}$ & Explicit & $\mathrm{I}, \mathrm{S}$ \\
\hline \multicolumn{3}{|c|}{ Additions from Current Course } \\
\hline Student Presentations & Both & $\mathrm{E}, \mathrm{S} / \mathrm{N}$ \\
\hline Assigned Readings & Explicit & $\mathrm{I}, \mathrm{N}$ \\
\hline Field Trips & Tacit & E, $N$ \\
\hline Green Materials (ID) & Tacit & $\mathrm{I}, \mathrm{N}$ \\
\hline $\begin{array}{c}\text { Homework - design } \\
\text { problems }\end{array}$ & Explicit & $\mathrm{I}, \mathrm{N}$ \\
\hline Pavement Mapping & Tacit & $\mathrm{I}, \mathrm{N}$ \\
\hline PowerPoint lessons & Explicit & $\mathrm{I}, \mathrm{S}$ \\
\hline
\end{tabular}

While all students have their individual MBTI preferences, the goal is not to tailor the course to the specific preferences of any one student, but to ensure that course pedagogy is diverse and fully inclusive of all learning styles. By linking the assessed dichotomies to each classroom session, it was clear that the course delivery methods being utilized were not well representative of a variety of different learning preferences. Through the process of solely evaluating the classroom instruction, not including the laboratory periods, it was clear that the primary classroom delivery method was explicit (Figure 1). In the pre-2010 CE Materials course, the majority of the coursework catered to students who prefer the $\mathrm{I}$ and $\mathrm{S}$ dichotomies - those who prefer to learn via explicit or articulated knowledge. After the first iteration of changes to the post- 2010 course, there continued to be a clear lack of coursework designed for the $\mathrm{E}$ and $\mathrm{N}$ learning preferences - those students who prefer to learn via tacit or experiential knowledge (Figure 2). Reflecting on the original goal of this assessment, creating an exciting and inclusive classroom experience, there continued to be a need to alter course pedagogy from the dominant learning style to create a classroom experience that would appeal to a more diverse student population. By framing the course such that all student learning preferences are fully represented, a more inclusive learning environment is fostered resulting in a broader population of students being educated and inspired as they progress through this foundational course.

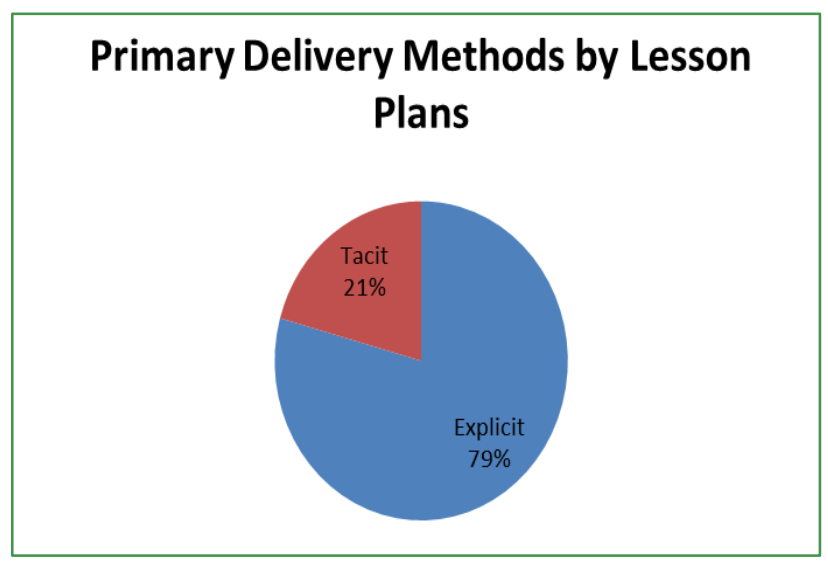

Figure 1. Primary Delivery Lesson in Current Course

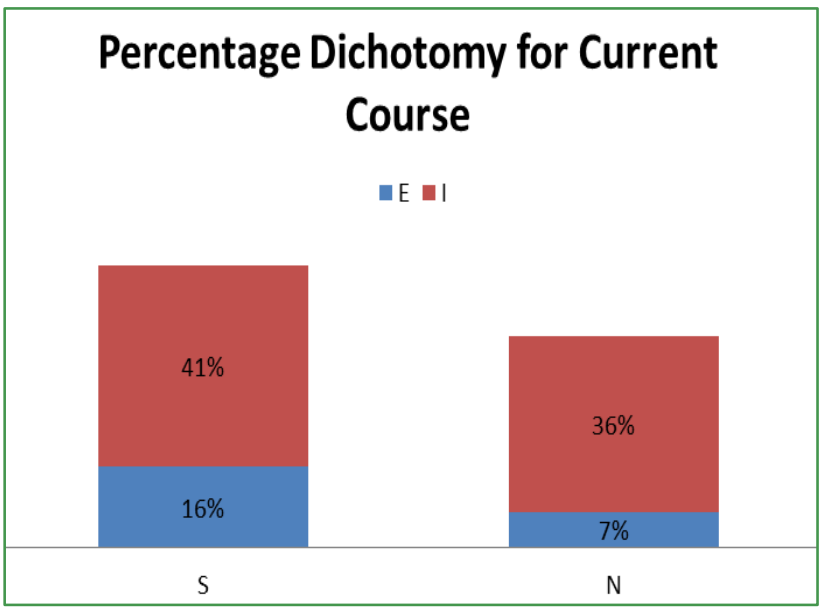

Figure 2. Dichotomy Percentage in Current Course

\section{CE Materials Current Course Adoptions}

After the first iteration of significant course changes in CE Materials, more tacit instruction methods were incorporated with the goal of appealing to learners who prefer the $\mathrm{E}$ and $\mathrm{N}$ dichotomies. As stated, initially tacit instruction was solely utilized in CE Materials during the laboratory periods. Therefore, labs appealed to the students presenting the I and $\mathrm{S}$ dichotomies and the classroom portion of the course appealed to students preferring the $\mathrm{E}$ and $\mathrm{N}$ dichotomies. Many students found this disconnect frustrating. After the first iteration of change to this course, the following course modifications were made:

1) Student 5 Minute Presentations

2) Sustainable Material Identification

3) Hot Mixed Asphalt (HMA) Pavement Mapping

\section{Student 5 Minute Presentations}

Short student lead presentations were incorporated into the course and became part of the student's overall course grade. For the 5 minute presentation, the student was charged with identifying and researching a contemporary civil engineering 
method or material and presenting that method or material to the class. Each student is required to give one presentation and the presentations are scattered throughout the semester.

This small, yet effective assignment, has added tremendous benefit to the course and student learning process. First, the assignment appeals to the E dichotomy but has both a tacit and explicit component. The student completing the research and the presentation has a tacit experience while their classmates, listening to the presentation, have an explicit experience. Because the assignment charges the students with finding a novel topic, new materials and methods are introduced into the classroom. Additionally, the students take ownership of these new topics because they are selecting topics of interest to them. The assignment is intentionally vague, giving the students the freedom to not only pick a topic but also present the material in either a $\mathrm{S}$ or $\mathrm{N}$ fashion. This freedom stimulates the interactive thinking process that appeals to a variety of learning preferences and also makes the presentation memorable for not just the presenters, but also their peers.

\section{Sustainable Material Identification}

The emerging field of sustainable materials is vast and comprehensive. This topic can easily fill several 75-minute class periods or could be truncated to one quick PowerPoint presentation, an explicit delivery method. However, in an effort to avoid overwhelming the students with the broad spectrum of sustainable materials and maximize their retention of the material, the instructors created a "green material scavenger hunt." Each student is tasked with researching a different, niche sustainable topic at the beginning of the class period. After a short period of time the students are then asked to informally present the material to their classmates; both the research and the presentation happened during the same class period.

Unlike the 5 minute presentations, the student does not have the freedom to choose their own topic, however, similar to the presentations he/she does have the freedom to present the material in whichever manner he/she chooses. The students are given a specific topic, (i.e. green roofs) but they are given no guidance on what to present about the topic. This vagueness, again, provides the student the opportunity to discuss the material in terms of bigger picture or matter of fact. This tacit delivery method increases the student's comprehension because he/she is forced to learn the material well enough to briefly present it. In addition to improved knowledge retention, both the green material scavenger hunt and the 5 minute presentations, provide the students an opportunity to speak in front of their peers and become more comfortable presenting material.

\section{HMA Pavement Mapping}

Distress pavement mapping was also successfully introduced into the course as an alternative to a standard classroom meeting. In class prior to the pavement mapping exercise, a PowerPoint presentation, coupled with chalkboard notes, identifies for students the various degrees of asphalt pavement failure, i.e. longitudinal cracking, potholes, etc. During the following class period, the students go outside where they are tasked with mapping a certain portion of distressed pavement on campus. The students are placed into groups and given separate sections of the pavement to map. Positive feedback from the students, both verbally and during assessment, reaffirms that this tacit classroom activity improves the overall student retention of distress identification. Coupling the initial explicit learning environment with the tacit pavement mapping activity reaches a broader range of student learning types and ensures that all students are exposed to this element of the course in a method that is most meaningful to them.

\section{Future Course Proposed Changes}

Even with current course alterations, the percentage of primary classroom deliver methods clearly favors the explicit learner. To appeal to both dichotomies more equally, this course could benefit from additional tacit instruction. In an effort to add more tacit instruction to the curriculum, two additional changes are planned for incorporation in the coming semester:

1) Student in class research and presentation

2) Guest Speakers

\section{Student in-class Research and Presentation}

Several topics were identified as potential areas for students to informally present the material to their classmates, similar to the green material scavenger hunt previously adopted into the course. The instructors noted that the course can take advantage of the introductory topics which are generally not complex, but require only the presenting of basic facts, such as the material's properties. The general outline for this type of class would be first the instructors would divide the class material into different samples. Ideally, the instructor will have actual materials for this purpose, to help the students identify the physical material. After forming groups, the students would first pick a sample, at random. The students will then spend the next 20-minutes, of the 75-minute period, researching their sample. The instructors would provide a handout with questions that the students would be required to answer. They would be allowed to use their textbooks, the library website and other reference material to answer the questions. The remainder of the class would be spent with the students presenting the material to their classmates. From the beginning of the class period, it would be made evident that the students are responsible for learning all the material, and the instructors would not be reiterating the topics.

The benefit of this type of instruction is two-fold. First, having the students identify samples and research different topics would make the lecture more interactive, and therefore create a tacit learning experience. Next, group work appeals to the extroverted student, however listening to the presentations and taking notes appeals to the introverted 
student. Both the $\mathrm{S}$ and $\mathrm{N}$ dichotomies are also met with this type of lesson plan. After meeting the basic requirements, the students will have the freedom to focus on whichever aspect of the material is most interesting to them. Depending on their preference this could be a bigger picture presentation $(\mathrm{N})$ or a more matter of fact presentation $(\mathrm{S})$.

The three course topics that have been identified as plausible for this type of classroom lecture are geosynthetics, engineered wood products and the mechanical properties of corrosion. These topics were identified because they can be presented broadly, can be simplified when providing an overview and the instructors can realistically provide physical samples to the students to use/analyze.

\section{Guest Speakers}

Inviting guest speakers into the classroom can be categorized as either a tacit or explicit. If a guest speaker discusses the material simply in a way that the instructor might present the material, i.e. a PowerPoint presentation, then the lecture is an explicit one. However, if the guest speakers have a more interactive lesson then the presentation becomes tacit. To ensure guest speakers are the latter, specific lessons are considered. To ensure a tacit guest speaker, the course instructors will only use guest speakers that would be able to give a more interactive lesson, based on the nature of their expertise and personality.

Two topics that were considered for interactive guest speakers were the pavement construction of Portland cement concrete and hot mixed asphalt. Ideally, the instructors will be able to reach out to construction managers of local ongoing pavement projects. The intention would be for the students to be able to walk a construction site while the guest speaker was explaining the intricacies of placing pavement. The class may have to start out with a brief lecture, in the classroom, explaining the overall process and major construction equipment. Then, the students can walk onsite while the speaker enforces the lesson.

This instruction would be a primarily tacit instruction due to the interactive nature of walking into a construction site. The lesson could appeal to the E and I as well as the S and N dichotomies. The main challenge posed with this type of instruction is finding a local construction project the students could visit within the allotted classroom time as well as the appropriate guest speaker.

\section{Evaluation of Proposed Course Alterations}

The overall proposed changes of the course would add additional tacit delivery methods to the course. Altering 5 classroom lectures would result in $62 \%$ explicit instruction and 38\% tacit instruction (Figure 3). However, if the laboratory sessions are included in the tacit vs. explicit count, the delivery method break down swings to more tacit than explicit instruction (Figure 4). For a course that has historically been viewed as "boring" by the students, due to the focus on memorization, a slightly more tacit approach is sought. In addition, the implementation of the new material dramatically increases the percentage of lessons that will appeal to students who prefer the E dichotomy in this course. Depending on the student learning preference and the manner in which they present materials assigned to them, these additions could potentially increase the $\mathrm{N}$ dichotomy of the course as well. Changes presented in this paper are aiding the CE Materials instructors in achieving their objective of reaching different learning preferences (Figure 5).

\section{Proposed Primary Delivery Methods, Classroom Instruction Only}

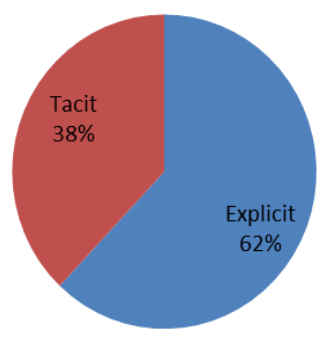

Figure 3. Proposed Primary Delivery Methods

\section{Proposed Primary Delivery Methods (including Laboratory schedule)}

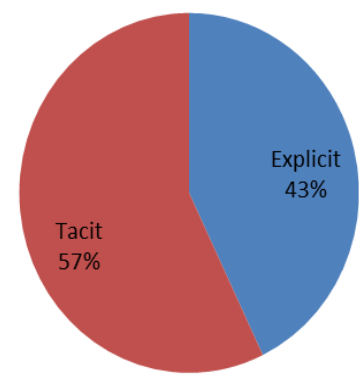

Figure 4. Proposed Delivery Methods (Including Lab)

\section{Percentage Dichotomy after Proposed Changes}

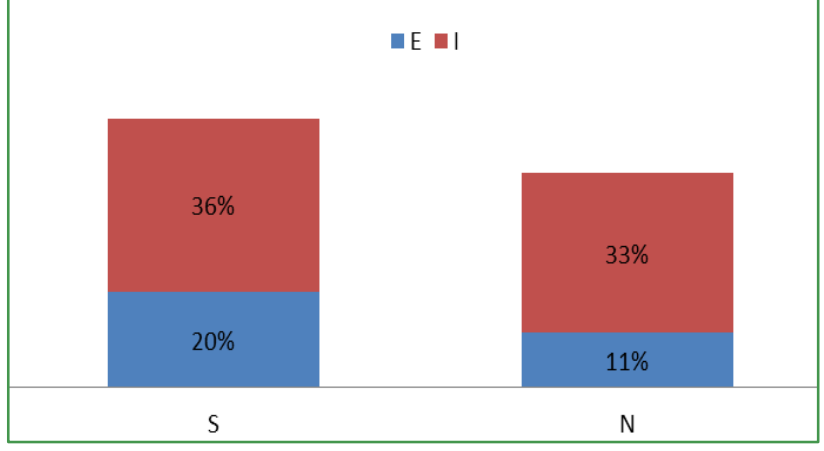

Figure 5. Proposed Dichotomy Changes 


\section{Conclusions}

The civil engineering students at the USCGA have incredible demands placed on their time. As such, they are forced to prioritize their efforts on a daily basis. As instructors, our goal is to maximize their retention of our course material in a stringent engineering curriculum surrounded by military demands. The goal of this assessment is to determine how to present material in a manner that most benefits the students. To accomplish this objective, lesson delivery methods were varied based on MBTI personality indicators and explicit vs. tacit learning styles. Ideally, existing and proposed changes will further excite students about the course material providing the ability for the course to reach a broader base audience. By redesigning a "boring" required course and improving the appeal of the material, the intent is to enhance student retention of basic knowledge in a professional setting. Future course changes that will be implemented include the infusion of more tacit learning approach.

Table 2. CE Materials End of Course Survey Questions

\begin{tabular}{|l|}
\hline \multicolumn{1}{|c|}{ Survey Questions } \\
\hline Understanding of concepts \\
\hline Instructor helped understand practical significance of concepts \\
\hline Describe eng prop of civil engineering materials \\
\hline Describe major functions \& list applications of geosynthetic materials \\
\hline $\begin{array}{l}\text { Identify \& discuss relevance of properties to selection, application, spec } \\
\text { \& performance as const. material }\end{array}$ \\
\hline Design PCC mix \\
\hline Design AC mix \\
\hline $\begin{array}{l}\text { Conduct fundamental lab test (collect, analyze data) to determine prop. } \\
\text { \& design parameters }\end{array}$ \\
\hline Prepare a professional report documenting lab tests \& results \\
\hline
\end{tabular}

A more thorough and quantitative feedback will be achieved during the execution of the course once all changes are implemented. Currently, the course instructors utilize daily "one minute feedback" forms [3]. These forms, provided to a random sample of the students each class period, ask the sample to, in their own words, (1) identify the main point of the lesson, (2) identify the most interesting thing covered, and (3) identify the "muddiest" point of the lesson. In addition, an end of course survey is distributed that attempts to grasp the students' perception of their own ability. The survey asks each student to "rate your ability to do the following..." Then the 9 course objectives (table 2) were stated so the students may assess their individual competence in each category. The results of that course survey from 2013-2015 showed no clear distinction throughout the three years (figure 6). The initial implementation of course changes began in fall 2013. Comparing and contrasting past feedback forms with the future course will assist this assessment team in identifying whether the changes made to the course are more inclusive to a broader range of preferred learning styles.

\section{CEM End of Course Survey}

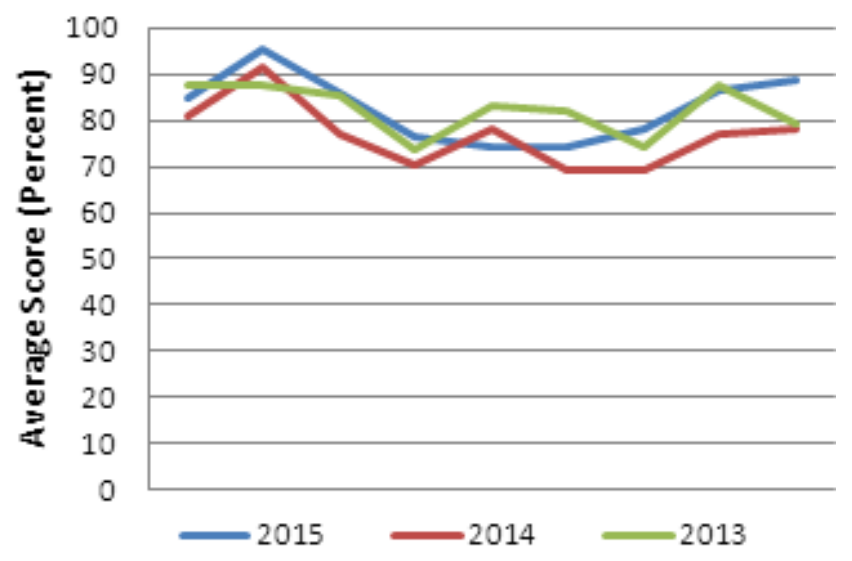

Figure 6. CE Materials End of Course Survey Results Comparison

Moving forward, further evaluation will take place after the additional course changes have been implemented. It is important to note, however, that some of the long-term learning will not show up on end of course surveys. The knowledge that the students actually retain beyond the semester long course cannot adequately be measured or reflected in class feedback forms.

\section{REFERENCES}

[1] The United States Coast Guard Academy. ABET Self-Study Report for the Civil Engineering Program New London, CT: The United States Coast Guard Academy. June 25, 2013.

[2] Myers, Isabel and McCaulley, Mary, MBTI Manual Third Edition, CPP, NY, 2009 pg. 3

[3] Filene, Peter, The Joy of Teaching, UNC Press, NC, 2005 pg. 105 